\title{
Ischemic Nucleotide Breakdown Increases During Cardiac Development Due to Drop in Adenosine Anabolism/Catabolism Ratio
}

\author{
Jan Willem de Jong, Elisabeth Keijzer, Tom Huizer and Bob Schoutsen \\ Cardiochemical Laboratory, Thoraxcenter, Erasmus Universily Rollerdam, Rotlerdam, The Netherlands
}

(Received 7 February 1990, accepted in revised form 9 April 1990)

\begin{abstract}
J. W. de Jong, E. Keyzer, T. Huizer and B. Schoutsen. Ischemic Nucleotide Breakdown Increases During Cardiac Development Due to Drop in Adenosine Anabolism/Catabolism Ratio. Journal of Molecular and Cellular Cardiology (1990) 22, 000-000. Our earlier work on reperfusion showed that adult rat hearts released almost twice as much purine nucleosides and oxypurines as newborn hearts did [Am J Physiol 254 (1988) H1091]. A change in the ratio anabolism/catabolism of adenosine could be responsible for this effect. We therefore measured the activity of adenosine kinase, adenosine deaminase, nucleoside phosphorylase and xanthine oxidoreductase in homogenates of hearts and myocytes from neonatal and adult rats. In hearts the activity of adenosine deaminase and nucleoside phosphorylase $(10-20 \mathrm{U} / \mathrm{g}$ protein) changed relatively little. However, adenosine kinase activity decreased from 1.3 to $0.6 \mathrm{U} / \mathrm{g}(\mu<0.025)$, and xanthine oxidoreductase activity increased from 0.02 to $0.85 \mathrm{U} / \mathrm{g}$ $(P<0.005)$. Thus the ratio in activity of these rate-limiting enzymes for anabolism and catabolism dropped from 68 to 0.68 during cardiac development. In contrast, the ratio in myocytes remained unchanged (about 23 ). The large difference in adenosine anabolism/catabolism ratio, observed in heart homogenates, could explain why ATP breakdown due to hypoxia is lower in neonatal than in adult heart. Because this change is absent in myocytes, we speculate that mainly endothelial activities of adenosine kinase and xanthine oxidoreductase are responsible for this shift in purine metabolism during development.
\end{abstract}

Key Words: Adenosine deaminase; Adenosine kinase; Adult; Age; Development; Myocyte; Neonate; Nucleoside phosphorylase; Purine catabolism; Rat heart; Xanthine oxidoreductase.

\section{Introduction}

ATP metabolism plays an important role in myocardial function, e.g., contractility, ion transport, vasodilation. Most studies on this topic focus on adult heart. Consequently, relatively little is known about ATP metabolism in the newborn heart. We showed recently large age-related differences in cardiac purine release following ischemia [I]. We hypothesized that a change in anabolic/catabolic pathways of adenosine was responsible for this phenomenon. Therefore, we studied the activity of adenosine kinase, adenosine deaminase, nucleoside phosphorylase and xanthine oxidoreductase in (homogenates of) rat hearts and cardiomyocytes. Part of the results has been published in abstract form [13].

\section{Materials and Methods}

\section{Chemicals}

All chemicals used were of the highest grade available. Adenosine, inosine, hypoxanthine and uric acid were supplied by Janssen Chimica (Beerse, Belgium). Xanthine and [8${ }^{14} \mathrm{C}$ ] xanthine were from Boehringer (Mannheim, FRG) and Amersham (Little Chalfont, UK), respectively. Collagenase, hyaluronidase and calf serum were bought from Boehringer, M199 cell culture medium from Gibco (Paisley, UK). 5'-Iodotubercidine was obtained from Research Biochemicals (Natick, MA., USA), erythro-9-(2-hydroxy-3nonyl)adenine $\cdot \mathrm{HCl}$ from Burroughs Wellcome (Research Triangle Park, N.C.,

Please address all correspondence to: Dr J. W. de Jong, Cardiochemical Laboratory, Thoraxcenter, Erasmus University Rotterdam, P.O. Box 1738, 3000 DR Rotterdam, The Netherlands. 
USA), alpha, beta-methylene-adenosine- $5^{\prime}$ diphosphate and bovine serum albumin from Sigma (St. Louis, Mo., USA). Allopurinol came from Wellcome (Beckenham, UK).

\section{Neonatal preparations}

Hearts were used of Sprague-Dawley rats (two days old; IFFA-Credo, Lyon, France). The sucklings were killed by decapitation. For the preparation of heart homogenates $(5 \%$ $w / v)$, a pool of ten ventricles was washed with $154 \mathrm{~mm} \mathrm{NaCl}, \mathrm{O}^{\circ} \mathrm{C}$, then minced in a Virtis blender and a Potter-Elvehjem homogenizer at $\mathrm{O}^{\circ} \mathrm{C}$. The homogenization buffer consisted of: $10 \mathrm{~mm}$ Tricine, $1 \mathrm{~mm}$ EDTA, $0.25 \mathrm{~m}$ sucrose, $\mathrm{pH}$ 7.4. Homogenates were stored below $-80^{\circ} \mathrm{C}$. Neonatal cells were prepared and cultured according to Link et al. [20]. Myocytes were separated from non-muscular cells with the method of Blondel et al. [6]. After a culture period of 2 days, the cells were washed three times with $154 \mathrm{~mm} \mathrm{NaCl}$, scraped from the Petri dishes into the homogenization buffer, and stored in liquid nitrogen. The purity of the cell culture was about $80 \%$ (May-Grünwald staining).

\section{Adult preparations}

Adult rats (about four months old; source: see above) were sedated intraperitoneally with 30-60 $\mathrm{mg}$ pentobarbitone. The hearts were isolated and the atria removed. To eliminate blood, the hearts were flushed retrogradely with $154 \mathrm{~mm} \mathrm{NaCl}$. The ventricles were homogenized essentially as described for the neonatal hearts. For the preparation of cardiomyocytes, the procedure of Farmer et al. [16] was partly followed. A modified Tyrode solution [17] was used with $0.1 \%$ collagenase, $0.1 \%$ hyaluronidase, $0.1 \%$ albumin and $50 \mu \mathrm{m}$ $\mathrm{CaCl}_{2}$ [16]. Hearts were perfused with this solution in a recirculating way at $37^{\circ} \mathrm{C}$ for 30-40 min [21]. Then the ventricles were cut from the perfusion apparatus and torn apart using two forceps. After 10 min incubation with the Tyrode solution (albumin raised to $1 \%$ ), the remainder of the tissue was gently suspended further with a serological $10-\mathrm{ml}$ pipette [21] and filtered through a $200-\mu \mathrm{m}$ mesh sieve. The cells were washed in the Tyrode solution (no enzymes, $2 \%$ albumin, sterile [16]) once at $1 \times \mathrm{g}$ and twice at $12 \times \mathrm{g}$ for 1 min. Subsequently, the cells were suspended in sterile M199 medium, containing $4 \%$ fetal calf serum. They were purified using the method of Piper et al. [2I] and kept in culture for 1 day. Then the cells were collected in homogenization buffer and stored in liquid nitrogen. With phase-contrast microscopy, only myocytes could be detected in the preparation.

\section{Assays}

Just before the assay of the (cytosolic) enzymes, carried out at $30^{\circ} \mathrm{C}$, the samples $(2-5$ $\mathrm{ml}$ ) were thawed, sonicated (M2/70, MSE, Crawley, UK) twice at $\mathrm{O}^{\circ} \mathrm{C}$ for $30 \mathrm{~s}$, and spun in a Mikroliter centrifuge (Hettich, Tuttlingen, FRG) at $4^{\circ} \mathrm{C}$ for $5 \mathrm{~min}$. Adenosine kinase was assayed with the radiometric method described by De Jong et al. [11,12]. Adenosine deaminase activity was determined according to Coddington et al. [8], using $45 \mu \mathrm{M}$ adenosine. If the activity was too low for detection with the Hitachi U-2000 double-beam spectrophotometer, products were measured by high-performance liquid chromatography [18]. Nucleoside phosphorylase was tetermined at $293 \mathrm{~nm}$, using $0.1 \mathrm{M} \mathrm{K}-\mathrm{PO}_{4} \mathrm{pH} 7.4$, $0.25 \mathrm{~mm}$ inosine and $0.2 \mathrm{U}$ xanthine oxidoreductase (see Boehringer catalogue). Xanthine oxidoreductase was measured according to Schoutsen et al. [23]. Protein was assayed with Coomassie Brilliant Blue (BioRad Laboratories, Munich, FRG) according to Bradford [7], using bovine serum albumin as the standard.

\section{Statistics}

Statistical analysis was done with Student's $t$ test for unpaired variates (two-tailed). Data are given as means \pm s.E. Differences with $P<0.05$ were considered significant.

\section{Results}

The adenosine kinase activity measured in ventricular homogenates decreased from $1.3 \pm 0.2 \mathrm{U} / \mathrm{g}$ protein in neonatal hearts to $0.58 \pm 0.12 \mathrm{U} / \mathrm{g}(P<0.025)$ in adult hearts (Fig. 1). In isolated myocytes it also decreased about two-fold with increasing age (Fig. 1). In 


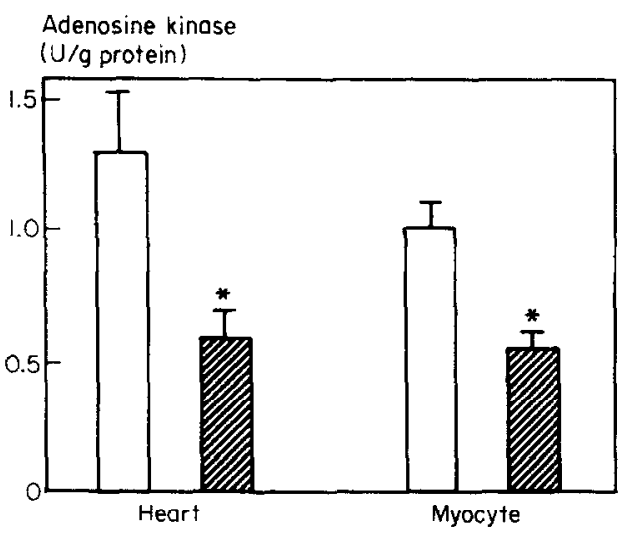

FIGURE 1. Adenosine kinase activities in ventricles and myccytes from neonatal (open bars) and adult (hatched bars) rat hearts. Mean values are given with s.E. $(n=6) .{ }^{*} P<0.025$ vs. neonatal.

neonatal heart cells, we measured $1.02 \pm 0.10$ $\mathrm{U} / \mathrm{g}$, in adult cells $0.56 \pm 0.06 \mathrm{U} / \mathrm{g}$ $(P<0.005)$. The specific activities of the ventricular and myocyte preparations did not differ significantly.

The adenosine deaminase activity in ventricular homogenates was unaffected by age: $12.9 \pm 1.1 \mathrm{U} / \mathrm{g}$ protein in neonatal hearts and $10.9 \pm 0.2 \mathrm{U} / \mathrm{g}$ in adult hearts (Fig. 2). However, isolated myocytes differed in this respect: $6.8 \pm 0.6 \mathrm{U} / \mathrm{g}$ (neonatal) versus $2.6 \pm 0.2 \mathrm{U} / \mathrm{g}$ (adult, $P<0.001$ ). The specific activity in both cell preparations was lower $(P<0.001)$ than that in the ventricular preparations.

The activity of nucleoside phosphorylase decreased from $20.6 \pm 1.9 \mathrm{U} / \mathrm{g}$ protein in neo-
Nucleoside phosphorylose (U/g protein)

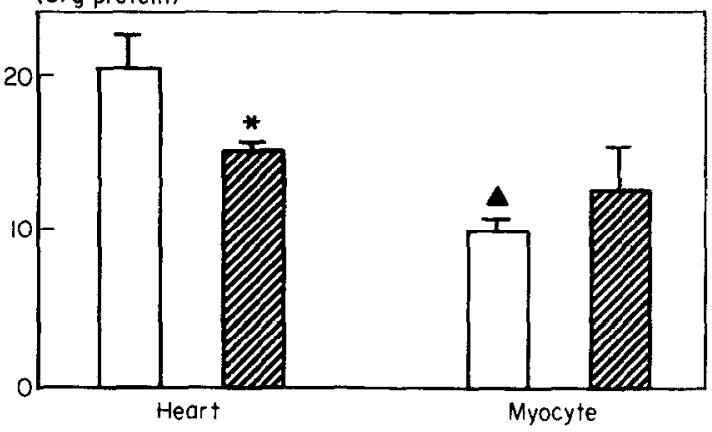

FIGURE 3. Nucleoside phosphorylase activities in ventricles and myocytes from neonatal (open bars) and adult (hatched bars) hearts. Mean values with s.e. $n=36$. ${ }^{*} P<0.025$ vs. neonatal; ${ }^{\wedge} P<0.001$ vs. whole heart.

natal hearts to $15.1 \pm 0.6 \mathrm{U} / \mathrm{g}(P<0.025)$ in adult hearts (Fig. 3). We found $10.0 \pm 0.7$ $\mathrm{U} / \mathrm{g}$ in neonatal myocytes, which was lower $(P<0.001)$ than that in whole hearts. Nucleoside phosphorylase activity in adult myocytes $(12 \pm 3 \mathrm{U} / \mathrm{g})$ did not differ significantly from that in neonatal myocytes or adult hearts.

In heart homogenates xanthine oxidoreductase increased in activity during development from $0.018 \pm 0.008$ to $0.85 \pm 0.15$ $\mathrm{U} / \mathrm{g}$ protein $(P<0.005$, Fig. 4$)$. In contrast, this change was absent in myocytes: $0.042 \pm 0.015 \mathrm{U} / \mathrm{g}$ (neonatal cells), $0.026 \pm 0.017 \mathrm{U} / \mathrm{g}$ (adult cells).

To check the specificity of the enzyme reactions studied, we tested several inhibitors in
Adenosine deaminase

(U/g protein)

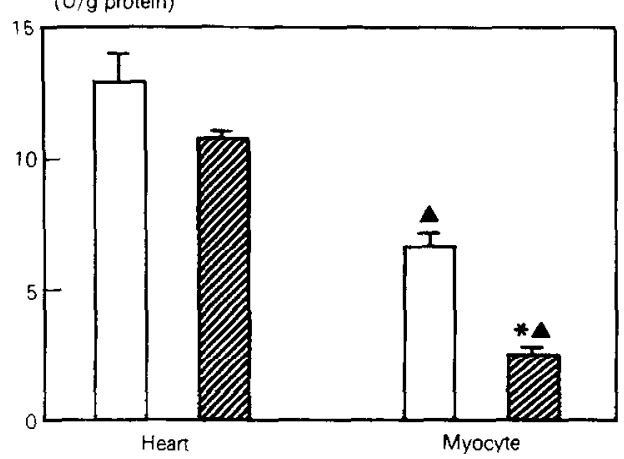

FIGURE 2. Adenosine deaminase activities in ventricles and myocytes from neonatal (open bars) and adult (hatched bars) hearts. Mean values with s.E. $(n=5-6)$. ${ }^{*} P<0.00$ l vs. neonatal; ${ }^{\star} P<0.001$ vs. whole heart.

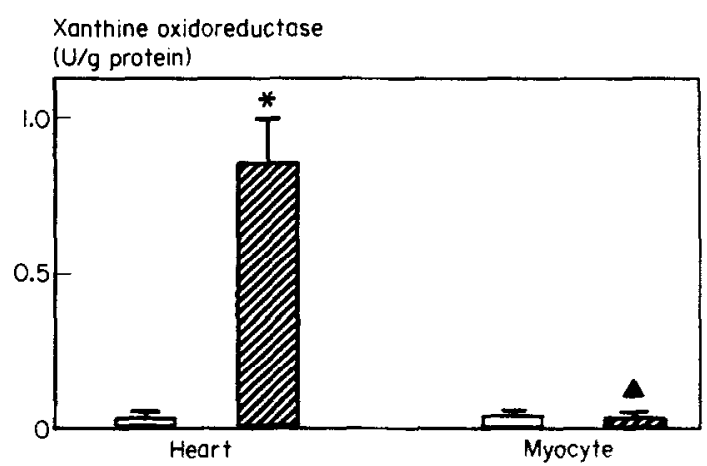

FIGURE 4. Xanthine oxidoreductase activities in ventricles and myocytes from neonatal (open bars) and adult (hatched bars) hearts. Mean values with s.e. $(n=4-6)$. ${ }^{*} P<0.005$ vs. neonatal; ${ }^{\wedge} P<0.005$ vs. whole heart. 
both neonatal and adult heart preparations. Erythro-9-(2-hydroxy-3-nonyl)adenine $\quad(10$ $\mu \mathrm{M})$ inhibited the adenosine deaminase activity by $98 \%, 5^{\prime}$-iodotubercidine $(5 \mu \mathrm{M})$ that of adenosine kinase by $96 \%$ [9]. Addition of the adenosine deaminase inhibitor [25] or alpha, beta-methylene-adenosine-5'-

diphosphate $\left(50 \mu_{\mathrm{M}}\right)$, a $5^{\prime}$-nucleotidase inhibitor [25], did not stimulate the adenosine kinase reaction, showing that adenosine deaminase and $5^{\prime}$-nucleotidase did not interfere with the assay. Allopurinol $(100 \mu \mathrm{M})$ inhibited the xanthine oxidoreductase activity $>98 \%[28]$.

\section{Discussion}

A number of cardiac enzymes involved in ATP breakdown vary with age $[24,27]$. During hypoxia nucleotides catabolize to purines, which may cross cell membranes. Using neonatal and adult heart, we compared the activities of adenosine kinase and adenosine deaminase, enzymes sharing adenosine as a substrate. In addition we measured nucleoside phosphorylase and xanthine oxidoreductase, enzymes responsible for the ultimate breakdown of nucleosides. We do not know whether the different enzymic activities observed are due to different amounts of enzymes; xanthine oxidoreductase can occur in an inactive form [26]. The inhibitor studies proved that our enzymic assays were specific.

\section{Adenosine kinase and adenosine deaminase}

A new finding is the difference in adenosine kinase activity between neonatal and 4-month old ventricles (Fig. 1). The activity in the latter had decreased more than twice. We found this change also in isolated cardiomyocytes. Regardless of age, the specific activities in whole heart and myocytes were similar. This indicates that the bulk of adenosine kinase is present in the myocytes, which make up most of the cardiac mass.

The adenosine deaminase activity in hearts and myocytes was substantially higher than that of adenosine kinase ( $c f$. Figs 1 and 2). It explains why deamination exceeds phosphorylation of adenosine in isolated, perfused hearts [10]. The enzymic measurements confirm the results of Arch and Newsholme [3] obtained in adult rat hearts. However, they contrast data from Dow et al. [15] who reported equal activities of the two enzymes in adult cardiomyoctes. The discrepancy is probably due to the differencc in assay temperature used (see ref. 2).

The activities of adenosine deaminase in neonatal and adult hearts did not differ (Fig. 2), confirming literature data [27]. On the other hand, the specific activity in neonatal myocytes was about half of that in heart homogenates; it decreased $60 \%$ during development (Fig. 2). This indicates that adenosine deaminase activity is not evenly distributed among cardiac cells, especially in adult heart. Similarly, Dow et al. [15] stated that most of the myocardial adenosine deaminase is not located in (adult) myocytes. We postulate that this catabolic activity resides mainly in the endothelial cells.

\section{Nucleoside phosphorylase and xanthine oxidoreductase}

Nucleoside phosphorylase activity in adult heart was somewhat lower than in neonatal heart (Fig. 3). This finding is in agreement with published data [27]. Neonatal myocytes contained half the activity observed in heart homogenates. The adult ventricular and cellular preparations showed comparable activity. We conclude that the early preponderance of nucleoside phosphorylase activity in noncardiac cells disappears later in life. We doubt that the enzyme in rat heart is predominantly located in endothelial cells, contrasting data for guinea-pig heart [22].

The data in Figure 4 confirm our earlier reports that xanthine oxidoreductase activity increases age-dependently [24]. Apparently this rise takes place almost exclusively outside the cardiomyocytes (Fig. 4), presumably in the microvascular endothelium $[4,19]$. We like to stress that xanthine oxidoreductase shows little activity in the (adult) heart of several species, including man [14].

\section{Anabolism versus catabolism}

The specific activities of adenosine kinase and xanthine oxidoreductase were more than ten times lower than those of the other enzymes. During development the ratio of the former, 
rate-limiting enzymes for anabolism and catabolism, dropped from 68 to 0.68 in ventricles. In contrast, the ratio in myocytes remained unchanged, i.e., about 23. We conclude that the large difference, observed in heart homogenates, explains why ATP breakdown due to hypoxia is less in neonatal than in adult heart. Because this change is absent in myocytes, we speculate that endothelial activities of adenosine kinase and xanthine oxidoreductase are responsible for this shift in purine metabolism during development. Could the urate produced by the adult heart of some species act as a radical scavenger and antioxidant $[2,5]$ ?

\section{Acknowledgement}

We are grateful for the secretarial assistance of Ms M. J. Kanters-Stam.

\section{References}

1 Achterberg, P. W., Nieukoop, A. S., Schoutsen, B., De Jong, J. W. Different ATP-catabolism in reperfused adult and newborn rat hearts Am J Physiol 254, H1091-H1098 (1988).

2 Ames, B. N., Cinthcart, R., Schwiers, E., Hochstein, P. Uric acid provides an antioxidant defense in humans against oxidant- and radical-caused aging and cancer: A hypothesis. Proc Natl Acad Sci USA 78, 68586862 (1981).

3 Аrch, J. R. S., Newsholme, E. A. Activities and some properties of 5 '-nucleotidase, adenosine kinase and adenosine deaminase in tissues from vertebrates and invertebrates in relation to the control of the concentration and the physiological role of adenosine. Biochem J 174, 965-977 (1978), Suppl Publ.

4 Becker, B. F., Gerlach, E. Uric acid, the major catabolite of cardiac adenine nucleotides and adenosine, originates in the coronary endothelium. In: Topics and Perspectives in Adenosine Research Gerlach, E., Becker, F. (Eds) Springer, Berlin/Heidelberg/New York, 209-222 (1987).

5 Becker, B. F., Reinholz, N., Ozçelik, T., Leipert, B., Gerlach, E. Utic acid as radical scavenger and antioxidant in the heart. Pflügers Arch 415, 127-135 (1989).

6 Blondel, B., Roijen, I., Cheneval, J. P. Heart cells in culture: A simple method for increasing the proportion of myoblasts. Experientia 27, 356-358 (1971).

7 BRADFORD, M. M. A rapid and sensitive method for the quantitation of microgram quantities of protein utilizing the principle of protein-dye binding. Anal Biochem 72, 248- 254 (1976).

8 Coddington, A. Some substrates and inhibitors of adenosine deaminase. Biochim Biophys Acta 99, $442-451$ (1965).

9 Daly, J. W. Adenosine receptors: Targets for future drugs. J Med Chem 25, 197-207 (1982).

10 De Jong, J. W. Phosphorylation and deamination of adenosine by the isolated, perfused rat heart. Biochim Biophys Acta 286, 252-259 (1972).

11 De Jong, J. W., Kalkman, C. Myocardial adenosine kinase: Activity and localization determined with rapid, radiometric assay. Biochim Biophys Acta 320, 388- 396 (1973).

12 De Jong, J. W., Keijzer, E., Urtendaal, M. P., Harmsen, E. Further purification of adenosine kinase from rat heart using affinity and ion-exchange chromatography. Anal Biochem 101, 407-412 (1980).

13 De Jonc, J. W., Schoutsen, B., Keijzer, E. Myocardial adenosine kinase activity decreases with age. J Mol Cell Cardiol 19, [Suppl 3] S16 (1987) (Abstr).

14 De Jong, J. W., Van Der Meer, P., Nieukoop, A. S., Huizer, T., Stroeve, R. J., Bos, E. Xanthine oxidoreductase activity in perfused heart of various species, including humans. Circ Res 67, (in press) (1990).

15 Dow, J. W., Bowditch, J., Nigdikar, S. V., Brown, A. K. Salvage mechanisms for regeneration of adenosine triphosphate in rat cardiac myocytes. Cardiovasc Res 21, 188-196 (1987).

16 Farmer, B. B., Mancina, M., Williams, E. S., Watanabe, A. M. Isolation of calcium tolerant myocytes from adult rat hearts: Review of the literature and description of a method. Life Sci 33, 1-18 (1983).

17 Harmen, E., De Tombe, P. P., De Jong, J. W., Achterberg, P. W. Enhanced ATP and GTP synthesis from hypoxanthine or inosine after myocardial ischemia. Am J Physiol 246, H37-H43 (1984).

18 Huizer, T, De Jong, J. W., Achterberg, P. W. Protection by bepridil against myocardial ATP-catabolism is probably due to negative inotropy. J Cardiovasc Pharmacol 10, 55-61 (1987).

19 Jarasch, E.-D., Grund, C., Bruder, G., Heid, H. W., Keenan, T. W., Franke, W. W. Localization of xanthine oxidase in mammary-gland epithelium and capillary endothelium. Cell 25, 67-82 (1981).

20 Link, G., Pinson, A., Hershko, C. Heart cells in culture: A model of myocardial iron overload and chelation. J Lab Clin Med 106, 147-153 (1985).

21 Piper, H. M., Probst, I., Schwartz, P., Hütter, F. J., Spieckermann, P. G. Culturing of calcium stable adult cardiac myocytes. J Mol Cell Cardiol 14, 397-412 (1982).

22 Rubro, R., Berne, R. M. Localization of purine and pyrimidine nucleoside plosphorylases in heart, kidney, and liver. Am J Physiol 239, H721-H730 (1980).

23 Schoutsen, B., De Jong, J. W., Harmen, E., De Tombe, P. P., Achterberg, P. W. Myocardial xanthine oxidase/dehydrogenase. Biochim Biophys Acta 762, 519-524 (1983). 
24 Schoutsen, B., De Jong, J. W. Age-dependent increase in xanthine oxidoreductase differs in various heart cell types. Circ Res 61, 604-607 (1987).

25 Schütz, W., Schrader, J., Gerlach, E. Different sites of adenosine formation in the heart. Am J Physiol 240, H963-H970 (1981).

26 Terada, L. S., Beghler, C. J., Banerjee, A., Brown, J. M., Grosso, M. A., Harken, A. H., McCord, J. M., ReprNe, J. E. Hyperoxia and self- or neutrophil-generated $\mathrm{O}_{2}$ metabolites inactivate xanthine oxidase. J Appl Physiol 65, 2349-2353 (1988).

27 WANG, T., TAN, Z.-T., WEBB, W. R. Postnatal changes in enzyme activities of rat myocardial adenine nucleotide catabolic pathway. Life Sci 10, 239-244 (1987).

28 Watts, R. W. E., Watts, J. E. M., Seggmiller, J. E. Xanthine oxidase activity in human tissues and its inhibition by allopurinol (4-hydroxypyrazolo[3,4-d]pyrimidine). J Lab Glin Med 66, 688-697 (1965). 